\title{
La adquisición de vocabulario dibujado en la educación primaria: El potencial de la memoria como herramienta metodológica
}

Cristina Rusiñol tinarusinol@hotmail.com Universidad de Barcelona, España

Reference

Rusiñol, Cristina; (2012) "La adquisición de vocabulario dibujado en la educación primaria: El potencial de la memoria como herramienta metodológica", p. 51-55. In: Barbosa, Helena; Quental, Joana [Eds]. Proceedings of the 2nd International Conference of Art, Illustration and Visual Culture in Infant and Primary Education. São Paulo: Blucher, 2015. ISSN 2318-695X, ISBN: 978-989-98185-0-7

DOI 10.5151/edupro-aivcipe-11

Desde el Departamento de Didáctica de Educación visual y plástica de la UB venimos realizando unos estudios con los que analizar la capacidad de asimilación del lenguaje del Dibujo en la infancia.

Los estudios han consistido en la implementación, en el último curso de primaria, de una serie de pruebas con las cuales los alumnos concretaron formas elementales predeterminadas. Dichos estudios surgen ante la problemática detectada en dos aspectos fundamentales: $\mathbf{1}$. Respecto a los contenidos: El reducido repertorio referencial dibujado. Manifiesto en la escasa cantidad de formas esquemáticas dibujadas por los alumnos. El hecho queda reflejado en la persistencia de los llamados "esquemas universales", dibujos que nos muestran formas vagas e imprecisas. Estos esquemas actúan a modo de prototipos "inmunizando" el aprendizaje analítico de particularidades. Dichos prototipos están ampliamente extendidos en el dibujo de numerosas instituciones educativas que ocupan no solo, el ciclo de primaria, sino que perviven y se enquistan durante la educación secundaria. 2. Respecto a las aptitudes: La incapacidad de formular relaciones entre forma y significado. Ejemplo genérico de ello serían las dificultades de distinción entre las formas particulares de mamíferos: como caballos, perros, vacas...

Nuestra aportación se centra en: 1. Mostrar estrategias para el desarrollo de la memoria cognitiva de las formas visuales y plásticas. Plantearnos una metodología que impulse de la facultad de ejercitar la memoria particular y analítica del conocimiento de las formas visuales. 2. Presentar una metodología que persiga consolidar un vocabulario básico de imágenes para cada una de las etapas educativas. En la lengua escrita queda claramente establecido que para redactar una narración comprensible se precisa un acopio mínimo de palabras. En el área de plástica esta asimilación se materializa a través de la concreción de formas dibujadas. La creación progresiva de un repertorio de imágenes abrirá las puertas a la creación y la riqueza expresiva del dibujo. Este fin claro en el caso de la literatura, parece haber quedado un tanto olvidado en nuestra área y, su didáctica ha sido poco resolutiva. 3. Reflexionar sobre la diferencia entre metodologías basadas en la copia, y en la asimilación del referente a través del ejercicio de la memorización formal. La interiorización del modelo, a través del método que proponemos, deja de ser una mera copia para convertirse en un proceso de asimilación personal. 4. Ofrecer una clasificación de distintas tipologías de esquemas. 5. Exponer ejercicios que reflejan el desarrollo en los diferentes niveles educativos.

La libertad como fuente exclusiva que debe formar a los alumnos ha ido, probablemente, mermando la capacidad para evaluar una imaginería sólida y personal. Subrayamos la importancia de potenciar estrategias basadas en la ejercitación de la memoria. Su uso debería ser revisado como factor para optimizar la interiorización personal de la forma dibujada en esta etapa educativa.

Dibujo, expresión plástica, didáctica visual, metodología docente. 
$2^{\text {nd }}$ International Conference Art, Illustration and Visual Culture in Infant and Primary Education $2^{\circ}$ Congreso Internacional

Arte, llustración y Cultura Visual en Educación Infantil y Primaria gresso Internacional

de Arte, llustracão e Cultura Visual

na Educação Infantil e Primária
Abstract

Keywords
At the Visual Teaching Education Department at UB (University of Barcelona), we have been doing some studies that analyze the assimilative capacity of the drawing language during childhood.

Studies have included the implementation in the final year of primary school, a series of tests in which students specify materialized elementary forms. These studies arrise to face the problems detected in two aspects: 1. Regarding the contents: The small repertoire of drawing reference. Manifest of the limited number of schematic shapes drawn by the students. The fact is reflected in the persistence of the so-called "universal schemes". Drawings that show us vague and imprecise shapes. Drawings showing ways vague and imprecise. These schemes act as prototypes "immunizing" learning analytical characteristics. These prototypes are widespread in the drawings of many educational institutions and are addressed not only tduring he primary cycle, but survive and stay during on the secondary education. 2. Regarding skills: The inability to formulate relationships between shape and meaning. A generic example of this would be the difficulty of distinguishing between the particular forms of mammals such as horses, dogs, cows...

Our contribution focuses on: 1. To show strategies for the development of cognitive memory of visual shapes. Ask for a methodology that encourages the faculty to exercise particular memory and analytical knowledge of visual and plastic arts forms. 2. Present a methodology that seeks to consolidate a basic vocabulary of images for each of the stages of education. In the written language is clear that to writing a comprehensible narrative essay requires a minimum of words. In the area of plastic arts this assimilation is realized through the realization of drawn shapes. The progressive creation of a repertoire of images opens the door to wealth creation and expressive drawing. This purpose that is clear in case of literature, seems to have been somewhat forgotten in our area and its teaching has been less decisive. 3. Reflecting on the difference between methodologies based on the copy, and the assimilation of the referent through the formal exercise of memorization. The internalization of the model, using the method we propose, is no longer a mere copy to become a personal assimilation process. 4 Provide a classification of different types of schemes. 5. Exposing exercises that reflect the development in the different educational levels. Freedom as a sole source that should train students has been , probably fading by impairing the ability to evaluate a strong and personal imagery. We stress the importance of empowering strategies based on memory training. It's use should be reviewed as a way to optimize the personal internalization of the drawn during thiseducational stage.

Drawing, art expresión, education of Art, teaching methology

\section{Introducción}

En el curso de las investigaciones que estamos llevando a cabo dentro de la formación artística del ciclo de primaria hemos podido detectar la existencia de una carencia en el aprendizaje. Desde la responsabilidad que nos brida el ejercicio de la docencia en el área de Didáctica de la Educación Visual y Plástica de la Formación de Profesorado de la Universidad de Barcelona creemos que se debe tener en consideración esta laguna. Esta ponencia pretende analizar esta problemática y aportar estrategias didácticas para fortalecer la enseñanza del lenguaje del dibujo en la educación primaria. Trataremos de fundamentar objetivos y clarificar metas a alcanzar en la enseñanza del Dibujo. Estas reflexiones, como en adelante veremos, apuntan a la necesaria revisión de didácticas que ejercitan la memoria de la forma.

Tras el análisis de más de 5000 dibujos de alumnos del último curso del ciclo educativo de la educación primaria hemos detectado que existe una problemática evidente en dos aspectos determinados:

1. La empobrecida capacidad del alumnado de formular relaciones entre forma y significado. Esta dificultad se refleja en el dibujo de la caracterización del listado de elementos sugerido. Este hecho queda reflejado un gran número de dibujos cuya imprecisión, en la formalización 
$2^{\text {nd }}$ International Conference Art, Illustration and Visual Culture in Infant and Primary Education $2^{\circ}$ Congreso Internacional

Arte, Ilustración y Cultura Visual en Educación Infantil y Primaria
${ }^{\circ}$ Congresso Internacional

de Arte, llustração e Cultura Visual

na Educação Infantil e Primária

de rasgos específicos para determinar el elemento que estaban tratando de dibujar, no adquiría significado. En un 73 \% de los dibujos analizados existen visibles carencias en la diferenciación de las forma particulares que esquematizan un modelo.

2. La dificultad por parte de un 86 \% de los alumnos sometidos a la prueba de asociar la dimensión del elemento respecto a la superficie de la hoja de papel.

Venimos realizando un estudio centrado en la observación del repertorio referencial que el niño tiene interiorizado al final del actual ciclo de la educación primaria. La metodología que hemos empleado para llevar a cabo esta investigación se desarrolla en dos sesiones de una hora en la que cada unos de los alumnos dibuja un listado de objetos en un tiempo concreto. El listado de objetos versa sobre elementos básicos dentro de lo que se podría considerar el imaginario infantil. En este listado aparecen cuatro mamíferos relacionados con el mundo animal; vaca, caballo, perro y oveja. En la segunda sesión se les da otro listado relacionado con el mundo del transporte donde aparecen otros cuatro objetos: Bicicleta, camión, moto y coche.

El objetivo de esta prueba es poder sacar ciertas conclusiones del conocimiento previo que tienen los alumnos que están en el final del ciclo formativo de primaria de un repertorio básico de elementos visuales. El tiempo estipulado para realizar dicha prueba es de una hora por sesión. Conscientemente se establece un tiempo para la realización de esta prueba más bien escaso Este condicionante temporal pretende llevar a estos alumnos a la realización de sus dibujos de una manera más bien esquemática. Además de este modo quedará reflejada la agilidad que estos alumnos tienen en la rememoración de los referentes que aparecen en el listado mencionado. Los materiales instrumentales que se les ofrece a los alumnos es un lápiz una goma y dos hojas Din 4 donde deberán dibujar los elementos individualmente en una cara del papel. Estas limitaciones invitan a una realización del dibujo a partir de un esfuerzo de síntesis, y a la reconstrucción de la forma a través de una materialización esquemática de la línea.

Los criterios seguidos en su análisis es la observación de:

1. La capacidad de plasmar el grado y el número de particularidades que alcanzan para describir cada uno de los elementos.

2. La agilidad mental que poseen estos alumnos para rememorar el referente mencionado en la lista para poder materializarlo en el papel

3. La capacidad de describir sintéticamente los rasgos de los referentes propuestos.

4. La previsión del alumno para calcular la cantidad de objetos que debe dibujar y el tiempo que posee para realizarlos.

5. La suficiencia del alumno para realizar asociaciones de dimensión entre los otros elementos del listado entre ellos en relación con la dimensión de la hoja o dicho de otro modo del soporte establecido

La elección de los referentes que hemos tomado para determinar los elementos que forman el listado se basaba en familias de elementos que se hallasen dentro de una misma unidad formal. De esta manera entre ellos existía una relación que ofrecía la posibilidad de observar como se habían diferenciado por sí mismos y entre ellos. Es decir, entre la vaca y el caballo existen algunas características similares como por ejemplo, el hecho de que ambos tienen cuatro patas, cola, y su posición de cuadrúpedos hace que su cabeza se halle adelantada en relación al cuerpo. En cambio, para encontrar sus diferencias se debe tener en cuenta; que la cabeza del caballo tiene una gran mandíbula, mientras que la de la vaca no se estrecha tanto en el morro. La curvatura del vientre también es un lugar que característicamente diferencia uno y otro animal. Esta diferenciación formal seguiría por la curvatura de su espalda, por la forma oval característica del muslo de las patas posteriores del caballo que poco tienen que ver con el cuarto trasero la vaca que por lo general es menos abultada. La toma de conciencia del valor de la forma caracterizada en aspectos de relaciones de anatomía comparada queda registrada a través del dibujo.

Nuestra propuesta en este ámbito educativo es mostrar una metodología fundamentada en la interiorización, a través de la memorización, de la forma particular. Una didáctica que 
persigue el objetivo de consolidar un "vocabulario" básico de imágenes para cada una de las etapas educativas del ciclo de primaria. Hemos adoptado la palabra "vocabulario", utilizado para designar el conjunto de palabras de un idioma, pues palabras y dibujos tienen en común su dependencia a la convención. El objeto sólo es posible para la mente a través de formas simbólicas, y los símbolos son intrínsecamente convencionales conforme a su referente. El símbolo no es intercambiable por el objeto sino a través de una convención. En realidad lo único que sabemos del objeto, la única verdad, es la que delimita el propio proceso de semiosis; el contenido mental delimita el objeto. La realidad posee cualidades desde un punto de vista plástico. Teóricamente este concepto se puede resumir en la consideración que afirma que toda imagen constituye un modelo de realidad. Lo que varía, por tanto, no es la relación que una imagen guarda con su referente, sino la manera diferente que tiene esa imagen de sustituir, interpretar, traducir..., es decir, de transformar a ese modelo de la realidad.

La convención requiere la intervención de artificios culturales y preceptúales que actúan como nexos articulando algunos de los aspectos de una estructura con significado. Pueden ser explícitos como en la lengua o implícitos como en las artes, pero en cualquier caso obedecen a pautas que regulan las relaciones entre los signos y sus referentes (designatum o denotatum). Es remarcable la tentativa por parte de la doctora Martínez García por intentar demostrar que el "dibujo de un niño es convencional, en cuanto las relaciones de correspondencia entre los objetos y sus equivalentes iconográficos obedecen a reglas predecibles e ínter subjetivas". (Martínez García, M. 2004: 38)

En la lengua escrita queda claramente establecido que para redactar una narración comprensible se precisa un acopio mínimo de palabras. Este fin claro en el caso de la literatura, parece haber quedado un tanto olvidado en nuestra área. Como resultado su didáctica ha sido poco resolutiva. El fomento en el área de plástica de la creación progresiva del repertorio de imágenes abrirá las puertas a la creación y la riqueza expresiva que irá poblando los dibujos. A este paralelismo cognoscitivo del niño entre los dos lenguajes, el verbal y el icónico, hace referencia el célebre pedagogo francés Celestine Freinet (Freinet, Celestine. 1979:32)

La edad idónea para implantar la propuesta metodología que muy sintéticamente presentaremos a continuación es en la etapa llamada por Lowenfield, esquemática. Esta etapa se desarrolla aproximadamente entre los 7 y 9 años. Igualmente en términos generales, en la etapa esquemática uno de los principales centros de interés es la representación simbólica de referentes. Luego en esta etapa la función prima sobre la forma. Según el pedagogo los niños para dibujar, en este periodo, parten de la premisa de que la sintetización de rasgos no solo sirve para significar un concepto universal del modelo representado. La adquisición de la forma esquemática debe ir más allá y penetrar en la adquisición de la representación de la forma del modelo progresivamente desde la generalidad hacia la representación de rasgos particulares del referente. En este punto para lograr la interiorización de los rasgos que determinan las características de los referentes, la capacidad memorística de retener la forma, nos parece un valor a incentivar metodológicamente.

Nuestra reflexión quiere resaltar que se considere como objetivo que los alumnos que atraviesan los ciclos de la enseñanza primaria interioricen progresivamente un ya mencionado vocabulario de elementos visuales y que sean capaces de plasmarlos mediante el lenguaje del dibujo. Esta acción pedagógica debería ser paulatinamente introducida en la metodología educativa empezando el proceso desde aquellas formas que simbolizasen a los referentes de manera más universal hasta de un modo gradual definiendo a los elementos por sus características particulares. La metodología que proponemos pretende que los alumnos asuman a los modelos mediante su interiorización, esta visión no intenta restaurar la vieja metodología basada en la copia de cartillas a la que tanto se oponían D. Ausbel y J. Novak. Nuestra propuesta trata de ofrecer una alternativa que didácticamente se desarrolla a través de la ejercitación de la memorización formal de los rasgos característicos del modelo pero que pretende a fin de cuentas que éste sea un aprendizaje significativo para el alumno.

La metodología en la práctica docente que proponemos se basa en:

- Conducir a los estudiantes a la observación de los referentes. En esta exposición por parte del docente se pondrá un especial énfasis en lo que se refiere al análisis de la forma en relación a la función que cumple en el objeto. Esta descripción de la forma debe ser 
$2^{\text {nd }}$ International Conference Art, Illustration and Visual Culture in Infant and Primary Education
Congresso Internacional

de Arte, llustração e Cultura Visual

na Educação Infantil e Primária

entendida como un contenido dentro de la enseñanza de la formación artística en este periodo.

- El desglose de las formas que articulan la transposición del referente en materiales plásticos. Esta actividad trata de ejercitar la percepción de la forma en los alumnos y su habilidad manual. Se trataría de desmontar en piezas la estructura de la representación de una determinada forma. Descubriendo que cuando éstas se encuentran asociadas entre ellas representan un referente y cuando se encuentran separadas son abstractas. Por otro lado al percibir sus formas desglosadas de esta asociación pueden percibir la particularidad de cada forma por separado. El objetivo de esta actividad persigue asumir la sutileza que encierra una forma completa así como también todas y cada una de sus partes. Una elipse, por ejemplo, fuera de la simplicidad que muestran sus formas geométricas permite en el medio artístico, la infinita variabilidad. La sutileza con la que se dibuje cada una de estas formas confiere una aproximación más fiel o más vaga en la representar un elemento.

- Conducir a la ejercitación a través de los medios plásticos de la capacidad en los alumnos de relación o diferenciación de las particularidades de los referentes a través de la forma. Para ello se debe encontrar un grupo de modelos que tengan a nivel formal una coherencia que establezca lazos de unión y de diferenciación entre unos y otros. Este es el caso de relacionar como mencionábamos anteriormente cuadrúpedos mamíferos cuyas diferencias y similitudes se pueden relacionar unas con otras.

- Se pondrá especial énfasis en desarrollar los ejercicios mediante diferentes técnicas. Con ello nos referimos a la utilización de diferentes materiales que ofrecen la posibilidad de conferir a los ejercicios diferentes acabados. Esta ejercitación y adquisición de estos contenidos según el medio plástico produce efectos muy diversos.

\section{Conclusión}

Con esta propuesta queremos poner de manifiesto la posibilidad de ofrecer alternativas didácticas a una problemática que parece que estamos detectando en el área de la formación artística (ciclos de primaria). Lo único que pretendemos es puntualizar la necesidad de encontrar un lugar para su ejercio dentro de los objetivos generales de los ciclos de la enseñanza de primaria y mejorar la capacidad de los alumnos desde la semantización de la diferencia formal. La interiorización de la forma, a través de la memoria, consideramos que dota a la capacidad creativa del alumno de un espacio expresivo personal y propio sin dejar de lado el conocimiento paulatino de la realidad. Por otra parte la capacidad de aprender a dibujar una amplia gama de elementos no deja de ofrecer al alumno mayor variedad de motivos con los que poblar las escenas. Así tendrá la posibilidad de utilizar este imaginario en las versiones libres de sus producciones plásticas.

\section{Referencias bibliográficas}

FREINET, Celestine. Los métodos naturales II. El aprendizaje del dibujo.

Ed. Fontanella.Barcelona, 1979.

E.H.GOMBRICH .Arte e ilusión. Editorial Debate, Barcelona, 1997

LECOQ DE BOISBAUDRAN, HORACE (1914).The training of the Memory in Art; And the Education of the Artist. Editorial General Books. La Vergne, 2009.

LOWENFELD, V y LAMBERT BRITAIN, U. Desarrollo de la capacidad creadora.

Ed. Buenos Aires, Kapelusz, 1972. 